\title{
Comparing Randomized Controlled Trials and Real-World Studies in Chronic Obstructive Pulmonary Disease Pharmacotherapy
}

This article was published in the following Dove Press journal:

International Journal of Chronic Obstructive Pulmonary Disease

\author{
Donald P Tashkin' \\ Alpesh N Amin ${ }^{2}$ \\ Edward M Kerwin ${ }^{3}$ \\ 'The Division of Pulmonary and Critical \\ Care Medicine, David Geffen School of \\ Medicine, University of California, Los \\ Angeles, CA, USA; ${ }^{2}$ Department of \\ Medicine, School of Medicine University \\ of California, Irvine, CA, USA; ${ }^{3}$ Crisor, \\ LLC Clinical Research Institute of \\ Southern Oregon, Medford, OR, USA
}

Correspondence: Donald P Tashkin David Geffen School of Medicine, University of California, Los Angeles, CA 90095, USA

Tel +I 3108253163

$\mathrm{Fax}+13102065088$

Email dtashkin@mednet.ucla.edu

\begin{abstract}
Analytic epidemiological studies cover a large spectrum of study methodologies, ranging from noninterventional observational studies (population-based, case-control, or cohort studies) to interventional studies (clinical trials). Herein, we review the different research methodologies or study designs and discuss their advantages and disadvantages in the context of chronic obstructive pulmonary disease (COPD) pharmacotherapy. Although randomized controlled trials (RCTs) are considered the "gold standard" for evaluating the efficacy and safety of an intervention, observational studies conducted in a real-world scenario are useful in providing evidence on the effectiveness of the intervention in clinical practice; understanding both efficacy and effectiveness is important from the clinician's perspective. Pragmatic clinical trials that use real-world data while retaining randomization bridge the gap between explanatory RCTs and noninterventional observational studies. Overall, different study designs have their associated advantages and disadvantages; together, findings from all types of studies bring about progress in clinical research as elucidated through examples from COPD research in this paper.
\end{abstract}

Keywords: clinical trials, COPD, pharmacotherapy, study designs

\section{Introduction}

Clinical research studies can be broadly classified as descriptive (eg, ecological studies or case reports) or analytic (Figure 1). ${ }^{1}$ Analytic studies span a large spectrum, ranging from noninterventional and observational real-world studies to interventional studies. ${ }^{1-5}$ Observational studies include cross-sectional, case-control, and longitudinal cohort studies, ${ }^{6}$ and interventional studies include explanatory randomized controlled trials (RCTs) and pragmatic clinical trials (PrCTs), which bridge the gap between explanatory RCTs and real-world observational studies. ${ }^{2,7}$ In addition to the difference in study types, study designs vary in many respects (eg, methodologies, temporal relationship, number of subjects enrolled, eligibility criteria, characteristics of included subjects, interventions administered, duration, assessments, and outcomes). These variations lead to inherent advantages and disadvantages; however, ultimately, the various study types and resultant data complement each other and form the building blocks of the research process.

Here, we review the different study types and discuss their advantages and disadvantages (also summarized in the supplementary video), in general and in the context of chronic obstructive pulmonary disease (COPD) pharmacotherapy, for the benefit of clinicians with more limited research experience. 


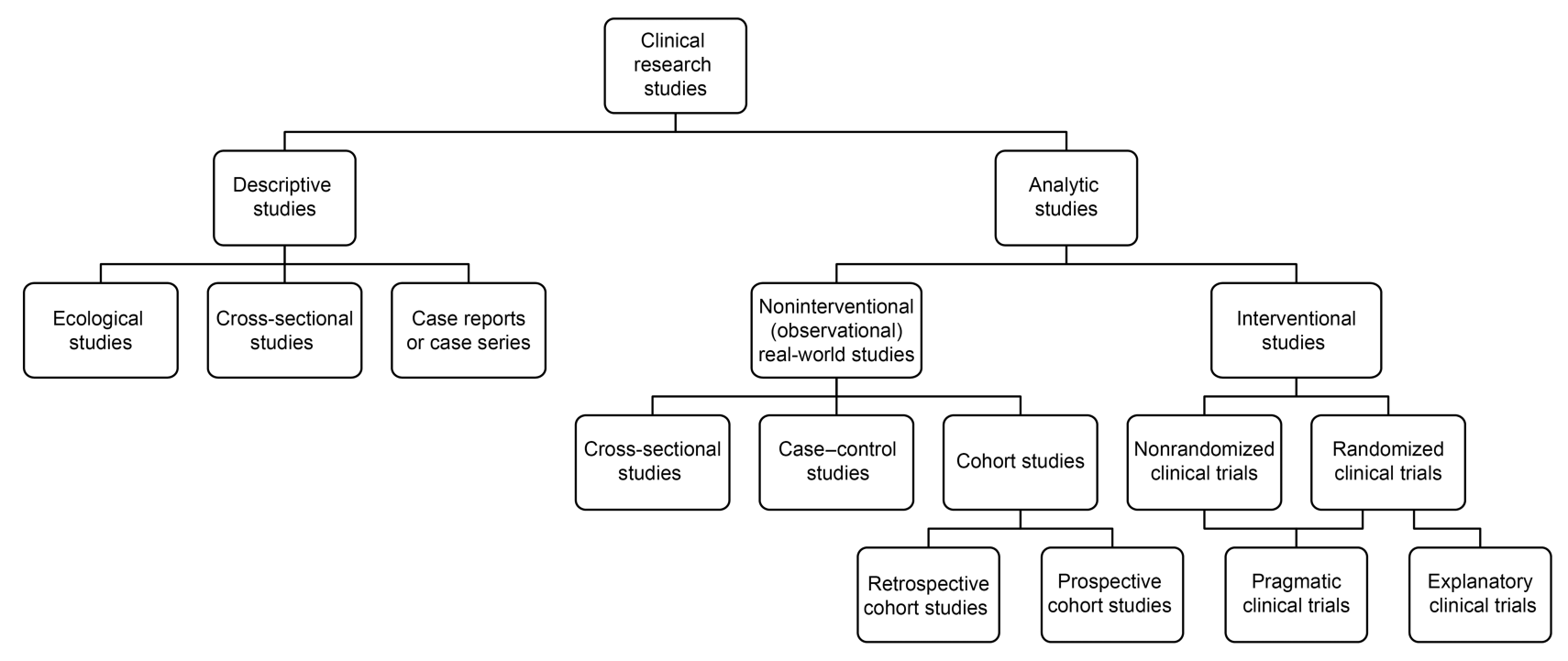

Figure I Overview of study designs.

\section{Process of Drug Development}

New drug development is a stepwise, rigorous, and prolonged process, ${ }^{8}$ typically involving preclinical studies, followed by phase 1 to 3 clinical trials, and phase 4 trials and other observational studies, which subsequently verify the results of phase 1 to 3 trials (Figure 2). The process may differ slightly for expanded indications (eg, additional age groups, other endpoints, and new diseases) for previously approved drugs.

\section{Study Designs}

\section{Explanatory Clinical Trials}

Clinical trials are prospective studies in which patients receive an intervention. The designs of such studies increase in complexity with each phase of the study (Figure 2). ${ }^{8,9}$ In general, phase 1 trials include small, nonrandomized, and noncomparative studies, whereas phase 2 trials may include randomized and comparative/controlled interventional studies. Early phase 1 and 2 trials often test or modify initial hypotheses, which are further evaluated in phase 3 and 4 trials.

Phase 1 trials are primarily safety and pharmacokinetic/ pharmacodynamic trials. These trials include a small number (20-80) of healthy volunteers who receive single or multiple doses of the investigational drug to determine dosing; document absorption, distribution, metabolism, and excretion (sometimes referred to as ADME studies); and identify short-term adverse effects. ${ }^{9}$

In phase 2 trials, safety and preliminary efficacy (the extent to which a drug can bring about its intended effect under ideal circumstances, such as in an $\mathrm{RCT}^{10}$ ) are assessed. ${ }^{9}$ Phase 2 trials are often blinded RCTs and include approximately 100 to 300 patients (ie, people with the

\begin{tabular}{|c||c|c|}
\hline $\begin{array}{c}\text { Preclinical } \\
\text { studies }\end{array}$ & $\begin{array}{c}\text { Small hypothesis } \\
\text {-generating/ } \\
\text { hypothesis- } \\
\text { testing Phase } 1 / 2 \\
\text { clinical trials or } \\
\text { dose-ranging } \\
\text { Phase } 2 \text { clinical } \\
\text { trials }\end{array}$ & $\begin{array}{c}\text { Larger RCTs } \\
\text { Phase } 3 \\
\text { clinical trials }\end{array}$ \\
& \\
\end{tabular}

\begin{tabular}{||c|c|}
\hline \multicolumn{2}{|c|}{ Real-world studies } \\
\hline Phase 4 & $\begin{array}{l}\text { - Retrospective/prospective } \\
\text { observational studies } \\
\text { Observational registries-/claims } \\
\text { database-/administrative } \\
\text { database-based studies }\end{array}$ \\
\cline { 1 - 2 } $\begin{array}{c}\text { Pragmatic } \\
\text { clinical trial }\end{array}$ & \\
\hline
\end{tabular}


disease under investigation) who receive either one or more doses of the investigational drug and/or standard-of-care treatment and/or placebo over a period of 1 to 4 weeks (to achieve steady state). Generally, the objective of the doseranging phase 2 trials is to determine the optimal dose(s) for evaluation in larger phase 3 trials in addition to assessing safety and preliminary efficacy. ${ }^{9}$

Phase 3 trials, comprising RCTs with specified eligibility criteria, are considered the "gold standard" for establishing the safety and efficacy of a drug. ${ }^{3,4}$ These RCTs are large scaleapproximately 1000-3000 patients; can be single-, double-, or triple-blinded; and are often conducted over a prolonged period of time. ${ }^{9}$ Patients are randomized to receive one or more doses of the investigational drug, placebo, and/or a commercially available comparator agent for weeks, months, or even years. Treatment safety, efficacy, and adherence are monitored using objective, validated endpoints with the help of home diaries and periodic assessments during visits at regular intervals. The number of patients and duration of the trial may vary depending upon the disease under consideration, stage of drug development, duration of previous trials, and chronicity of the disease. For example, if the primary endpoint is a reduction in exacerbations of COPD, the frequency of which varies according to season, a year-long study is generally preferred to reduce the confounding effect of seasonality. These trials aim to meet regulatory agency approval requirements to evaluate the long-term safety and efficacy of clinically relevant doses of the investigational drug compared with placebo and/ or a comparator agent, substantiated by sufficient statistical power generated with a large number of patients.

Phase 4 trials are usually prospective trials with active comparators (sometimes called head-to-head efficacy trials) or are open-label, noninterventional, observational studies conducted after regulatory approval; occasionally, these trials are agreed to by the study sponsor and are often required by regulatory approval authorities. ${ }^{11-13}$ The objective of these trials is to collect additional information about the safety (long-term risks and rare adverse events), efficacy of a drug on an expanded indication (eg, exacerbation reduction), effectiveness (the extent to which a drug achieves its intended effect in the usual clinical setting ${ }^{10}$ ), and optimal use of the investigational drug in the general patient population, as well as to evaluate the investigational drug in special patient populations that are usually excluded or difficult to include and follow-up in phase 3 RCTs. ${ }^{11}$

For rare diseases or orphan drugs, the number of phase 2 to 4 trials and the number of participants in each trial may be substantially reduced, and alternative clinical trial designs may be acceptable. ${ }^{14}$

Usually, statistical analyses in phase 2, 3, and 4 trials are conducted to assess whether or not the investigational drug has greater efficacy than placebo or an active control (a "superiority" design). Superiority evaluations require a prospective design with adequate statistical power, reliable objective endpoints, and adequate patient adherence. In superiority trials, usually an intent-to-treat (ITT) or an all-datacollected analysis is conducted ${ }^{15}$ by using appropriate analysis methods (eg, mixed models repeated measures [MMRM], analysis of variance [ANOVA], analysis of covariance [ANCOVA], Cox proportional hazard regression, or logistic regression ${ }^{16}$ ) to evaluate efficacy; however, other statistical methods may also be used. Traditionally, safety is assessed by the proportions of patients with adverse events, calculated as cumulative (at the end of the trial period) or cross-sectional (at each visit) percentages. ${ }^{16}$ Regulatory authorities often require two or more duplicate 12- to 24-week phase 3 efficacy trials and at least one phase 3 year-long safety trial (termed "pivotal trials") to adequately characterize the safety and efficacy of a new drug for approval. Given the seasonality of COPD exacerbations, long-term phase 3 trials of up to 12 months duration are recommended for the evaluation of the effect of new investigational drugs on this outcome or for the expansion of approved indications for already commercially available drugs. ${ }^{17}$

\section{Case Reports or Case Series}

Reports of individual cases or a series of cases provide retrospective safety and efficacy details, as well as other clinical parameters (eg, quality of life [QoL]) derived from cases of interest in their natural clinical setting; ${ }^{18}$ they can be based on either on-label (supporting the approved indication) or off-label (demonstrating a potential new or expanded indication) use of a drug. These cases are easy to report and can generate new research questions, although the generalizability of their findings is limited because of selection bias and lack of controls. ${ }^{18}$

\section{Real-World Observational Studies}

Real-world observational studies include large-scale cross-sectional, cohort, and case-control studies that do not employ randomization ${ }^{6}$ and may be population based (Table 1). Case-control studies are retrospective, while cohort studies may be prospective or retrospective. In these studies, investigators solely observe treatment effects, generally using administrative health databases, 
Table I Characteristics of RCTs, PrCTs, and Real-World Observational Studies, 2,7,9,19,21,97,98

\begin{tabular}{|c|c|c|c|}
\hline & RCTs & PrCTs & Real-World Observational Studies \\
\hline $\begin{array}{l}\text { General } \\
\text { information }\end{array}$ & $\begin{array}{l}\text { - Prospective design } \\
\text { - Usually phase } 2 \text { or } 3 \text { clinical trials } \\
\text { - Investigational drug vs placebo and/or } \\
\text { an active comparator(s) } \\
\text { - Provides "gold standard" evidence for } \\
\text { safety and/or efficacy of a drug }\end{array}$ & $\begin{array}{l}\text { - Prospective design } \\
\text { - Features of RCTs and real-world } \\
\text { observational studies } \\
\text { - Provides suggestive real-world evi- } \\
\text { dence on a therapeutic intervention's } \\
\text { value in real-world clinical practice } \\
\text { while maintaining the strength of } \\
\text { initial randomized treatment }\end{array}$ & $\begin{array}{l}\text { - Often retrospective design; can be } \\
\text { prospective or a combination of the } \\
\text { two } \\
\text { - Conducted using real-world data } \\
\text { from administrative health databases, } \\
\text { insurance and claims databases, and } \\
\text { registries }\end{array}$ \\
\hline Study population & $\begin{array}{l}\text { - Highly selective population(s) based } \\
\text { on defined inclusion (eg, age, sex, } \\
\text { severity of disease, concomitant } \\
\text { medications, and willingness to parti- } \\
\text { cipate) and exclusion (eg, comorbid- } \\
\text { ities, risk factors, and prior use of } \\
\text { study drugs or other confounding } \\
\text { medicines) criteria, with exclusions } \\
\text { applied to minimize the interference } \\
\text { of potential effect modifiers and } \\
\text { maximize the probability of demon- } \\
\text { strating a treatment effect }\end{array}$ & $\begin{array}{l}\text { - Broad population(s) from commu- } \\
\text { nity-based clinics } \\
\text { - Can include "all-comers" with the } \\
\text { disease under study }\end{array}$ & $\begin{array}{l}\text { - Potentially a very large population } \\
\text { - Less stringent selection criteria } \\
\text { clinical practice likely meeting the } \\
\text { exclusion criteria in RCTs (eg, } \\
\text { comorbidities, nonadherence, cross- } \\
\text { over to alternative medication, and } \\
\text { polypharmacy) }\end{array}$ \\
\hline Randomization & - Yes & - Usually & - No \\
\hline Comparability & $\begin{array}{l}\text { - Sample is randomized for uniform dis- } \\
\text { tribution of all known and unknown } \\
\text { factors affecting patient prognosis, } \\
\text { thus ensuring that differences in out- } \\
\text { comes are attributable to } \\
\text { intervention(s) } \\
\text { - NOTE: Baseline differences may still } \\
\text { occur in RCTs with smaller sample } \\
\text { sizes }\end{array}$ & $\begin{array}{l}\text { - Diverse populations taking new or } \\
\text { investigational therapies are enrolled } \\
\text { - Randomization helps ensure compar- } \\
\text { able treatment groups } \\
\text { - Limited generalizability of results } \\
\text { owing to lax adherence measures, } \\
\text { unrestricted treatment changes, and } \\
\text { lack of objective endpoints }\end{array}$ & $\begin{array}{l}\text { - Physician preferences, formulary sta- } \\
\text { tus, or costs may restrict new drug } \\
\text { prescriptions in difficult to treat or } \\
\text { treatment-resistant patients, poten- } \\
\text { tially biasing outcomes when com- } \\
\text { paring different treatments } \\
\text { - Although statistical adjustments can } \\
\text { be attempted for known variables } \\
\text { and comparison groups can be } \\
\text { matched using propensity scores, } \\
\text { adjustments for unknown variables } \\
\text { cannot be made }\end{array}$ \\
\hline $\begin{array}{l}\text { Study setting/ } \\
\text { data sources }\end{array}$ & $\begin{array}{l}\text { - Research centers, specialized trial } \\
\text { centers, and secondary or tertiary } \\
\text { hospitals } \\
\text { - Highly controlled environment }\end{array}$ & $\begin{array}{l}\text { - Usually community-based medical } \\
\text { clinics }\end{array}$ & $\begin{array}{l}\text { - Diverse routine clinical practice set- } \\
\text { tings, including primary care settings } \\
\text { - Large healthcare databases } \\
\text { - Registries }\end{array}$ \\
\hline $\begin{array}{l}\text { Assessment } \\
\text { burden }\end{array}$ & $\begin{array}{l}\text { - Demanding schedule of maintaining } \\
\text { records (eg, home diaries) and fre- } \\
\text { quent study visits }\end{array}$ & $\begin{array}{l}\text { - Periodic telephone or clinic evalua- } \\
\text { tions and recall questionnaires } \\
\text { - Few home diaries and visits } \\
\text { - Low follow-up demands }\end{array}$ & $\begin{array}{l}\text { - Regular, real-world physician-patient } \\
\text { interactions }\end{array}$ \\
\hline
\end{tabular}

(Continued) 
Table I (Continued).

\begin{tabular}{|c|c|c|c|}
\hline & RCTs & PrCTs & Real-World Observational Studies \\
\hline Data collection & $\begin{array}{l}\text { - Per-protocol using validated efficacy } \\
\text { endpoints such as PROs } \\
\text { - Daily electronic e-diaries } \\
\text { - Predefined scheduled visits } \\
\text { - Usually 6-10 follow-up visits, with } \\
\text { multiple objective endpoints and } \\
\text { PROs assessed at each visit }\end{array}$ & $\begin{array}{l}\text { - Subjective questionnaires or PROs } \\
\text { often used instead of objective pro- } \\
\text { cedure-based tests } \\
\text { - PROs provide suggestive evidence but } \\
\text { can be prone to errors resulting from } \\
\text { patient bias and potential lack of } \\
\text { validation } \\
\text { - Objective tests, such as e-diary data, } \\
\text { laboratory tests, and sequential lung } \\
\text { function tests, are not generally } \\
\text { obtained }\end{array}$ & $\begin{array}{l}\text { - Usually through hospital- or clinic- } \\
\text { based registries, where visits are per } \\
\text { standard of care, or insurance-based } \\
\text { claims } \\
\text { - Some modes of data collection (eg, } \\
\text { spirometry for COPD diagnosis or } \\
\text { assessment of treatment effective- } \\
\text { ness) may not be used in routine visits } \\
\text { - Overlapping/mistaken data (such as } \\
\text { diagnoses of both COPD and } \\
\text { asthma) may be entered in e-health } \\
\text { record databases. Some information } \\
\text { may be unavailable because data were } \\
\text { not entered in the e-health database }\end{array}$ \\
\hline Adherence & $\begin{array}{l}\text { - Strictly monitored by daily diaries or } \\
\text { dose counts } \\
\text { - Adherence is often near-complete or } \\
\text { maximum attainable because of con- } \\
\text { tinuous patient contact (eg, detailed } \\
\text { patient education, reminders, home } \\
\text { visits) }\end{array}$ & $\begin{array}{l}\text { - Adherence is loosely monitored with } \\
\text { intermittent dosing acceptable } \\
\text { - Annual number of prescription fills } \\
\text { may be estimated } \\
\text { - Adherence may be low and is reflec- } \\
\text { tive of real-world clinical scenarios }\end{array}$ & $\begin{array}{l}\text { - Annual prescription fills are often } \\
\text { measured } \\
\text { - Adherence is usually much lower than } \\
\text { that achieved in RCTs }\end{array}$ \\
\hline $\begin{array}{l}\text { Discontinuations/ } \\
\text { withdrawals }\end{array}$ & $\begin{array}{l}\text { - Patients with poor adherence or who } \\
\text { switch therapies are discontinued }\end{array}$ & $\begin{array}{l}\text { - Patients with poor adherence or who } \\
\text { switch therapies are included in the } \\
\text { analysis }\end{array}$ & $\begin{array}{l}\text { - Patients with poor adherence or who } \\
\text { switch therapies are included in the } \\
\text { analysis }\end{array}$ \\
\hline $\begin{array}{l}\text { Statistical design } \\
\text { and comparators }\end{array}$ & $\begin{array}{l}\text { - Usually, single- or double-blinded } \\
\text { treatments are administered to pre- } \\
\text { vent patient and clinician selection } \\
\text { bias } \\
\text { - Statistics prespecify numbers of } \\
\text { patients needed and power to } \\
\text { demonstrate superior efficacy for } \\
\text { primary endpoints } \\
\text { - Standard of care or placebo and/or an } \\
\text { active comparator are used for treat- } \\
\text { ment comparison } \\
\text { - Normally both per-protocol and } \\
\text { intention-to-treat analyses are } \\
\text { reported }\end{array}$ & $\begin{array}{l}\text { - Treatments are usually open-label } \\
\text { - Standard of care or an active treat- } \\
\text { ment comparator is used in super- } \\
\text { iority trials } \\
\text { - A highly effective comparator is used } \\
\text { in noninferiority trials } \\
\text { - Placebo is typically not dispensed } \\
\text { - Normally both per-protocol and } \\
\text { intention-to-treat analyses are } \\
\text { reported }\end{array}$ & $\begin{array}{l}\text { - Treatments are open-label by } \\
\text { prescription } \\
\text { - Usual care, which differs by patient } \\
\text { segment and country, can vary sub- } \\
\text { stantially across study centers }\end{array}$ \\
\hline Follow-up data & $\begin{array}{l}\text { - Follow-up duration is usually short } \\
\text { with frequent visits, often every } \\
8-12 \text { weeks; can be longer }\end{array}$ & $\begin{array}{l}\text { - Follow-up duration may be long, and } \\
\text { frequency is usually sparse with as } \\
\text { few as } 2 \text { or } 3 \text { mandatory visits over } \\
\text { a year }\end{array}$ & $\begin{array}{l}\text { - Follow-up duration may be substan- } \\
\text { tially long, often } \geq 1 \text { year, and fre- } \\
\text { quency of visits is determined by } \\
\text { patients and/or physicians per usual } \\
\text { practice }\end{array}$ \\
\hline
\end{tabular}

(Continued) 
Table I (Continued).

\begin{tabular}{|c|c|c|c|}
\hline & RCTs & PrCTs & Real-World Observational Studies \\
\hline Outcomes & $\begin{array}{l}\text { - Prospective primary, secondary, and } \\
\text { other efficacy and safety or pharma- } \\
\text { cokinetic endpoints are prespecified, } \\
\text { statistically powered, and collected to } \\
\text { objectively measure improvements vs } \\
\text { control/comparators } \\
\text { - Validated PRO questionnaires are used } \\
\text { - Health outcomes data are obtained } \\
\text { prospectively and concurrently, usually } \\
\text { through daily e-diaries or paper diaries } \\
\text { and frequent clinic visits } \\
\text { - Resource utilization data (eg, unsched- } \\
\text { uled clinic visits, emergency depart- } \\
\text { ment visits, and hospitalizations) and } \\
\text { risk vs benefit can be assessed } \\
\text { - Efficacy and safety outcomes assessed } \\
\text { should be biologically meaningful }\end{array}$ & $\begin{array}{l}\text { - Prospective primary and secondary } \\
\text { endpoints are prespecified for super- } \\
\text { iority or noninferiority analyses } \\
\text { - Few objective outcomes such as hos- } \\
\text { pitalization and mortality, and some } \\
\text { technician-administered outcome } \\
\text { tests may be completed } \\
\text { - Patient questionnaires are often used, } \\
\text { which are not always validated } \\
\text { - Rather than contemporaneous e-dia- } \\
\text { ries, data are usually collected retro- } \\
\text { spectively via periodic recall } \\
\text { questionnaires conducted via tele- } \\
\text { phonic interviews/conversations }\end{array}$ & $\begin{array}{l}\text { - Endpoints are retrospectively } \\
\text { selected to measure effectiveness, } \\
\text { safety, patient experience, PROs, } \\
\text { resource utilization, risk vs benefit } \\
\text { (relative effectiveness), etc, as deter- } \\
\text { mined by a study analysis plan pre- } \\
\text { pared a priori before data analysis } \\
\text { - Long-term effectiveness can be } \\
\text { assessed, and rare adverse events } \\
\text { may be identified } \\
\text { - Outcomes reported may be meaning- } \\
\text { ful for decision-making in routine } \\
\text { clinical practice }\end{array}$ \\
\hline Data quality & - Usually very good & - Variable & $\begin{array}{l}\text { - Concerns about sensitivity and spe- } \\
\text { cificity of data are present, given the } \\
\text { retrospective, nonrandomized design } \\
\text { and possible bias in matching } \\
\text { algorithms }\end{array}$ \\
\hline Generalizability & $\begin{array}{l}\text { Results are usually reproducible in the } \\
\text { population studied, and support drug } \\
\text { regulatory approval } \\
\text { - Results are applicable to patient } \\
\text { populations with disease characteris- } \\
\text { tics same or similar to those included } \\
\text { in RCTs }\end{array}$ & $\begin{array}{l}\text { - Findings may be hypothesis generating } \\
\text { or suggestive } \\
\text { - Can establish effectiveness in broad } \\
\text { real-world populations. However, } \\
\text { because of variable adherence, infre- } \\
\text { quent visits, and limited question- } \\
\text { naire-based endpoints, confirmation } \\
\text { by RCTs may also be needed }\end{array}$ & $\begin{array}{l}\text { - Results are applicable to a broad } \\
\text { range of healthcare databases, may } \\
\text { apply to real-life treatment users, and } \\
\text { may be generalizable to routine clin- } \\
\text { ical practice } \\
\text { - These studies are post hoc analyses, } \\
\text { and require confirmatory RCTs or } \\
\text { replicate observational studies before } \\
\text { results can be broadly accepted }\end{array}$ \\
\hline Validity & $\begin{array}{l}\text { Randomization and nondifferential } \\
\text { assignment are attempted to make } \\
\text { the treatment groups comparable at } \\
\text { baseline and ensure that the results } \\
\text { are valid and not confounded } \\
\text { - High level of scientific accuracy of } \\
\text { conclusions is ensured by strict } \\
\text { adherence, monitoring, and restric- } \\
\text { tions on disallowed medications, as } \\
\text { well as serial, contemporaneous col- } \\
\text { lection of objective endpoints }\end{array}$ & $\begin{array}{l}\text { - Prospective design and randomization } \\
\text { add credibility to these findings } \\
\text { - Findings are suggestive because of the } \\
\text { weak controls on adherence, con- } \\
\text { founding or alternative therapies, and } \\
\text { the limited endpoints assessed } \\
\text { - Broader patient populations are } \\
\text { enrolled } \\
\text { - If superiority is demonstrated, these } \\
\text { trials can provide compelling data for } \\
\text { clinicians and payers } \\
\text { - Findings of "noninferiority" are more } \\
\text { difficult to generalize because poor } \\
\text { adherence, crossing over between } \\
\text { therapies (if allowed), or soft end- } \\
\text { points can lead to scientific } \\
\text { uncertainty }\end{array}$ & $\begin{array}{l}\text { - Risk vs benefit assessment among } \\
\text { treatment groups may be con- } \\
\text { founded by incomparability of clinical } \\
\text { characteristics at baseline because of } \\
\text { differential prescribing } \\
\text { - Results may not be internally valid } \\
\text { and need to be interpreted with } \\
\text { caution }\end{array}$ \\
\hline
\end{tabular}

(Continued) 
Table I (Continued).

\begin{tabular}{|c|c|c|c|}
\hline & RCTs & PrCTs & Real-World Observational Studies \\
\hline Precision & $\begin{array}{l}\text { - Results may be reasonably precise in } \\
\text { RCTs of large sample size (>1000 } \\
\text { patients) }\end{array}$ & $\begin{array}{l}\text { - Precision is sacrificed to ensure } \\
\text { higher cost-effectiveness and } \\
\text { feasibility } \\
\text { - Evidence of superior efficacy com- } \\
\text { pared with usual care/standard } \\
\text { therapies can be demonstrated in } \\
\text { relatively small studies } \\
\text { - Larger samples are needed for ade- } \\
\text { quate power in "noninferiority" trial } \\
\text { designs because real-life patients may } \\
\text { not always be highly responsive or } \\
\text { adherent to treatments }\end{array}$ & $\begin{array}{l}\text { - A large sample size is likely to } \\
\text { increase the precision of the study }\end{array}$ \\
\hline Cost & - High cost per patient & $\begin{array}{l}\text { - Intermediate cost per patient } \\
\text { - Studies may be more expensive in } \\
\text { total because larger numbers of } \\
\text { patients are required, and real-world } \\
\text { patients may be less sensitive to drug } \\
\text { effects than highly selected patients }\end{array}$ & - Low cost per patient \\
\hline Value & $\begin{array}{l}\text { - Are of value for controlled scientific } \\
\text { analysis of treatment effectiveness } \\
\text { - Required for regulatory approval }\end{array}$ & $\begin{array}{l}\text { - Provide suggestive value to regulators } \\
\text { and payers } \\
\text { - May broaden populations appropriate } \\
\text { for clinical treatments }\end{array}$ & - Traditionally of value to payers \\
\hline
\end{tabular}

Abbreviations: COPD, chronic obstructive pulmonary disease; e-diary, electronic diary; e-health, electronic health; PrCT, pragmatic clinical trial; PRO, patient-reported outcome; RCT, randomized controlled trial.

claims databases, or registries; ${ }^{19}$ investigators have no control over the medical management of the patient or the data collected. These studies are characterized by the enrollment of real-world patients, lax controls on treatment adherence, use of concomitant medications or alternative therapies, and selection of endpoints for optimum feasibility; moreover, the endpoints may not be suitably objective or validated. Besides safety and clinical effectiveness, cost-effectiveness and other economical outcomes may also be assessed. ${ }^{19}$ When comparisons are made between the clinical effectiveness and/or safety of two or more different medications, propensity matching on selected clinical characteristics may be performed in an effort to minimize the impact of differences in these patient-related features. These studies are relatively cheaper and are especially useful when the disease of interest is rare, but can also be used when the disease of interest is common.

Cohort studies ${ }^{6}$ are prospective or retrospective studies conducted to determine the incidence and natural history of a disease or condition. Exposure to putative risk factors precedes the outcomes, and multiple outcomes can be studied using one cohort. However, prospective cohort studies are expensive and have a substantial risk of attrition, whereas retrospective cohort studies may be impacted by recall bias.

Case-control studies ${ }^{6}$ are retrospective studies in which individuals with and without the disease or condition of interest are matched (eg, age, sex,${ }^{20}$ duration of comorbid diseases, and severity markers for comorbid diseases). Severity matching is imperfect and can induce bias; therefore, both pre- and post-matched baseline severity characteristics should be reported. Case-control studies are useful for understanding exposure factors for rare diseases. ${ }^{6}$ In these studies, investigators review large healthcare database records and determine which individuals had the suspected exposure in the past. These studies are relatively cheaper (especially when compared with prospective cohort studies) and are feasible when the disease or condition of interest is rare. However, these studies are subject to biases such as sampling, observation, or recall bias. 


\section{Pragmatic Clinical Trials}

Key Features vs RCTs and Real-World Studies

PrCTs have some features of both RCTs and real-world observational studies (Table 1): ${ }^{2,19,21}$ like RCTs, they use prospective study designs and randomization, and like real-world studies, they involve broadly inclusive populations, representative of patients receiving the treatment in everyday clinical practice, and are conducted by healthcare professionals in community-based settings, where regular patient management is ensured while still tracking some measures of treatment adherence. In PrCTs, relevant outcomes important to inform optimal healthcare treatment decisions are captured, and appropriate active comparators are generally included instead of placebo. ${ }^{22}$ In RCTs, the benefits of an intervention may be overestimated and the harms may be underestimated because they are performed with relatively small and highly selective patient populations at research sites with experienced investigators. ${ }^{2}$ Therefore, findings from RCTs should not be used in formulating usual practice guidelines without further evaluation. ${ }^{23}$ In contrast, PrCTs provide effectiveness and safety estimates in large, real-world, diverse patient populations using broad inclusion and relatively few exclusion criteria. $^{21}$ Randomization in PrCTs confers some of the strengths of RCTs, such as credibility and limiting the allocation bias, to the PrCTs while providing external validity from the real-world component. ${ }^{24}$ PrCTs may also be designed to compare the effectiveness of alternative treatments or practice procedures not supported by the industry or the Food and Drug Administration (FDA) ${ }^{25}$ and allow recording of hospitalization and mortality throughout the study duration. Apart from objective clinical endpoints, inclusion of cost-effectiveness and adoption endpoints in PrCTs is critical for decision-making by health systems. Therefore, PrCTs can provide true risk/ benefit assessments and value of a medicine in a routine care setting, allowing healthcare practitioners and payers to make informed decisions. ${ }^{23}$

The limitations of PrCTs should, however, be noteddepending on whether they more closely mimic RCTs or real-world observational studies, PrCTs may have weak controls on adherence to therapy, ${ }^{28}$ permit cross-over to alternative therapies, ${ }^{28}$ and/or lack or include fewer objective, procedure-based outcome measures compared to RCTs. PrCTs may rely on alternative endpoints ${ }^{22}$ based on in-office or telephone questionnaires, which may provide suggestive evidence in some cases. On the other hand, lower adherence to therapies in PrCTs compared with RCTs is more reflective of the real-world clinical scenarios in $\mathrm{COPD}^{29}$ and contributes to the enhanced external validity of the results.

As discussed, the key aspects of trial designs differ substantially between RCTs and PrCTs. Researchers can use the PRagmatic Explanatory Continuum Indicator Summary-2 (PRECIS-2) tool to make study design decisions befitting the intended use of the trial. ${ }^{26}$ The applicability of real-world evidence (RWE) in research is expanding. With the 21st Century Cures Act, drug manufacturers can submit RWE instead of RCT results to support the expansion of additional indications for previously approved drugs. ${ }^{27}$

\section{Pragmatic Clinical Trials: Design Considerations}

Study populations in PrCTs represent real-world populations likely to be prescribed treatment resembling routine clinical practice. With randomization and real-world use, the approximate effectiveness and safety of such interventions can be evaluated by establishing "superiority" vs usual care or standard treatment (ie, superiority trials), ${ }^{30}$ or by showing "noninferiority" vs well-established therapies (ie, comparative effectiveness trials). ${ }^{31}$

Active-controlled superiority trials may require larger sample sizes than placebo-controlled trials, ${ }^{32}$ sometimes requiring several hundred patients per treatment arm to have enough statistical power to detect a superiority benefit. When the "superiority" of an intervention vs a control arm is evaluated in a PrCT, a prespecified statistical analysis plan (similar to RCTs with analysis methods such as MMRM or ANCOVA) is followed, and significant improvements in primary and secondary endpoints are sought (typically with $P<0.05$ ).

In comparative effectiveness trials, a carefully selected "noninferiority limit" is prospectively specified to ensure that a similar high level of clinical benefit is achieved for both the new and established treatments. ${ }^{30}$ A noninferiority trial aims to establish that the intervention is not worse than its comparator by a prespecified degree, which is known as the "noninferiority limit or margin". ${ }^{33}$ Statistical analyses need to be prespecified and of high rigor for noninferiority trials, with stringent noninferiority limits. High adherence to treatment and low use of confounding therapies are important. Otherwise, sloppy design or implementation features can lead to a false noninferiority finding, thus 
erroneously concluding an inferior treatment to be noninferior. ${ }^{15,34}$ Both per-protocol and ITT analyses are typically performed; however, unlike in superiority trials (where the ITT approach is considered conservative because it is likely to lead to a treatment effect closer to having no effect), the ITT approach is not conservative in noninferiority or equivalence trials because it can bias towards the null, which may lead to false claims of noninferiority or equivalence. ${ }^{35}$ Usually, the sample size required to demonstrate noninferiority in an activecontrolled trial is substantially larger (sometimes impossibly larger) than that for a placebo-controlled superiority trial; ${ }^{15,30}$ small sample sizes may reduce the statistical power for proving noninferiority. ${ }^{30}$

When well-conducted PrCTs report key differences or strong evidence for noninferiority between treatments, the findings may be applicable to larger, real-world populations, and the generated RWE can help clinicians understand the effectiveness and safety of the drug in clinical practice settings.

Comparing and contrasting the characteristics of RCTs, PrCTs, and real-world observational studies (Table 1) help to understand how these designs complement each other and can cumulatively create comprehensive evidence. Ideally, clinical research should address questions that are relevant to the target audience. To that effect, researchers could use the effective dissemination and implementation frameworks proposed by leading funding agencies, such as the National Heart, Lung, and Blood Institute and Patient-Centered Outcomes Research Institute. ${ }^{36,37}$

\section{Use of Different Research Methodologies in the Evaluation of COPD Pharmacotherapy}

Determining an optimum treatment for COPD has been a conundrum for many decades. Researchers often focus on improving lung function, respiratory symptoms, and QoL; preventing and treating exacerbations; and minimizing morbidity and mortality. ${ }^{38-40}$ Prevention of exacerbations to reduce morbidity has been crucial in COPD studies conducted as early as the mid-twentieth century. ${ }^{38,39}$

\section{Small Randomized/Nonrandomized Studies}

Occasionally, small nonrandomized or randomized trials (pilot studies) with or without adequate statistical power are used to determine the feasibility of a therapeutic approach which, when successful, can lead to larger clinical trials. For example, a series of studies were conducted to assess the benefit of antibiotics in treating COPD exacerbations. Elmes et al conducted an RCT based on previous research which demonstrated that exacerbations of chronic bronchitis were usually associated with pathogenic bacterial proliferation. ${ }^{38}$ Benefits of prophylactic oxytetracycline at the beginning of a suspected COPD exacerbation were assessed (as days ill and days off work; no lung function reported) in patients with chronic bronchitis. Among 88 patients who reported 146 exacerbations, exacerbation-associated loss of work time in the intervention group was half of that in the control group. Three decades later, Anthonisen et al documented their findings in a similar but slightly larger RCT with a crossover component conducted over 3.5 years in 173 patients. ${ }^{41}$ Of the 362 exacerbations, 182 and 180 were treated with an antibiotic and a placebo, respectively. With a treatment success of $68.1 \%$ vs $55.0 \% \quad(P<0.01)$, a significant benefit was observed with antibiotic vs placebo use. In a much larger, well-designed and appropriately powered, parallel-group, prospective RCT by Albert et al, approximately three further decades later, 1142 patients were randomized to receive azithromycin $(n=570)$ or placebo $(n=572)$ in addition to usual care for 1 year. $^{42}$ Patients in the azithromycin group had a significantly longer median time to first exacerbation, fewer exacerbations, lower risk of acute exacerbations, and greater improvement in St. George's Respiratory Questionnaire (SGRQ) scores than those in the placebo group (all $P<0.05$ ). Findings from a subgroup analysis showed that antibiotic efficacy was confined to former smokers. Results also indicated a significantly higher risk of hearing impairment in the azithromycin group $(P<0.05)$.

Similar to small, nonrandomized or randomized trials, a series of individual RCTs (N-of-1 RCTs) may provide preliminary data that could be confirmed in larger clinical trials. In a series of $27 \mathrm{~N}$-of-1 RCTs, long-term ambulatory oxygen therapy did not improve QoL (as measured by the Chronic Respiratory Questionnaire and the SGRQ) in patients with COPD; the general application of long-term ambulatory oxygen therapy was found to be not justifiable for patients with COPD and transient exertional hypoxemia who did not satisfy the criteria for mortality reduction. ${ }^{43}$ However, two patients were oxygen responders, leading the authors to conclude that select patients can be identified in N-of-1 RCTs who may benefit from long-term ambulatory oxygen therapy. Continuous oxygen therapy conferred a survival advantage specifically in 
patients with chronic obstructive lung disease with significant resting hypoxemia in the Nocturnal Oxygen Therapy Trial (NOTT) and Medical Research Council (MRC) studies. $^{44,45}$ However, long-term supplemental oxygen did not improve clinical outcomes in the Long-Term Oxygen Treatment Trial (LOTT), a large, multicenter, parallel-group RCT of 738 patients with COPD and moderate (less severe) resting or exercise-induced desaturation who were followed for 1 to 6 years. ${ }^{46}$

\section{Large Pivotal RCTs}

Overall, well-conducted, large, pivotal RCTs have led to the approval of new drugs or drug combinations for COPD treatment (Table 2). The efficacy of single bronchodilators (long-acting $\beta_{2}$-agonist [LABA] or long-acting muscarinic antagonist [LAMA]), dual bronchodilators (LABA + LAMA), and triple therapy (LABA + LAMA + inhaled corticosteroid $[\mathrm{ICS}]^{47}$ ) has been assessed in phase 3 and 4 clinical trials, which exemplify variations in RCTs with respect to design, population, and outcomes. The clinical development of tiotropium (an inhaled LAMA) and roflumilast (an oral phosphodiesterase-4 inhibitor), for example, exemplify the trajectory of different research methodologies - from preclinical studies through different phases of clinical trials.

Niewoehner et al first demonstrated that tiotropium significantly reduced COPD exacerbations in patients with moderate-to-severe COPD in a clinical trial of 6-month duration. ${ }^{48}$ This finding was further corroborated in the UPLIFT trial, a much larger phase 3 trial with approximately 6000 patients with moderate-to-very severe COPD who were followed for 4 years. ${ }^{49}$ Historically, tiotropium was delivered as a dry powder inhaled through HandiHaler ${ }^{\mathbb{B}}$ (tiotropium dry powder inhaler [DPI]), but later, it became available as an inhalation solution delivered via Respimat ${ }^{\circledR}$, a soft mist inhaler (SMI; tiotropium SMI). Further development led to the dual bronchodilator formulation of tiotropium + olodaterol $(5+5 \mu \mathrm{g}$; a fixed-dose LAMA + LABA). The development of tiotropium began with ipratropium, the first approved anticholinergic that has been shown to be safe and efficacious in both COPD and asthma treatment. ${ }^{50}$ In initial in vitro studies, tiotropium - although structurally similar to ipratropium - had a substantially higher affinity (6- to 20-fold), greater M3 receptor selectivity, and a slower dissociation profile and, hence, longer duration of action than ipratropium. $^{51,52}$ The high potency, slow onset, and long duration of effect of tiotropium were confirmed in the airways of guinea pigs and humans. ${ }^{53}$ The dose-related bronchodilator activity of tiotropium in COPD was demonstrated in an open-label, dose-escalation, crossover, pilot study of five single-inhalation doses of tiotropium $(10-160 \mu \mathrm{g} ; \mathrm{N}=6){ }^{54}$ The efficacy of tiotropium in COPD was further confirmed in a phase 2, 4-week, dose-ranging $\mathrm{RCT}(\mathrm{N}=169)$; the once-daily, 18- $\mu \mathrm{g}$ dose was well tolerated and, thus, selected for long-term trials. ${ }^{55}$ In a larger RCT $(\mathrm{N}=288), 18 \mu \mathrm{g}$ once-daily tiotropium DPI was significantly more efficacious than ipratropium ( $40 \mu \mathrm{g}$, four times daily), with a comparable safety profile over 13 weeks. ${ }^{56}$ Patients in this trial continued into a 1-year RCT and their results, combined with results from another identical 1-year RCT of patients with COPD, confirmed an acceptable safety profile and significantly greater efficacy of tiotropium $18 \mu \mathrm{g}$ once daily vs ipratropium in improving dyspnea, reducing exacerbations, and improving health-related QoL and lung function. ${ }^{40}$

The efficacy and tolerability of different doses of once-daily tiotropium SMI (5 and $10 \mu \mathrm{g}$ ) were compared with that of $18 \mu \mathrm{g}$ tiotropium DPI in preliminary studies, ${ }^{57,58}$ and results facilitated the transition from tiotropium DPI to tiotropium SMI. Based on the available breadth of evidence, tiotropium DPI was used as an active comparator to assess the efficacy and safety of once-daily tiotropium SMI in pivotal trials. Further key trials of tiotropium monotherapy or dual bronchodilator therapy with tiotropium + olodaterol $(5+5 \mu \mathrm{g})$ are summarized in Table 2. Of interest, initial studies of 1-year duration on efficacy and safety of tiotropium SMI indicated a numerical imbalance in the all-cause mortality signal in the tiotropium groups compared with placebo. ${ }^{59,60}$ However, this finding directly conflicted with the results of UPLIFT, a large phase 3 trial with approximately 6000 patients, in which tiotropium DPI treatment was associated with significantly lower mortality compared with placebo during the 4-year study duration. ${ }^{49}$ Subsequently, TIOSPIR, a large phase 3 trial with over 17,000 patients, which compared mortality and other safety endpoints between tiotropium SMI and tiotropium DPI, corroborated the findings concerning the safety of tiotropium. ${ }^{61}$ With comparable cardiovascular safety profiles for tiotropium SMI and tiotropium DPI, TIOSPIR refuted the concern that tiotropium SMI may have additional cardiovascular risks. This highlights the importance of large, well-designed, and adequately powered phase 3/4 RCTs to establish reliable efficacy and safety for new pharmacotherapies. 
Table 2 Examples of Pivotal and Subsequent Randomized Controlled Trials for COPD Pharmacotherapies

\begin{tabular}{|c|c|c|c|c|}
\hline $\begin{array}{l}\text { Study } \\
\text { Name }\end{array}$ & Study Type & Study Results & Drug Comparators & Duration \\
\hline \multicolumn{5}{|c|}{ Tiotropium (LAMA) ${ }^{48}$} \\
\hline $\begin{array}{l}\text { Niewoehner } \\
\text { et } \mathrm{al}^{48}\end{array}$ & $\begin{array}{l}\text { A parallel-group, randomized, } \\
\text { double-blind, placebo- } \\
\text { controlled trial }(\mathrm{N}=1829)\end{array}$ & $\begin{array}{l}\text { Tiotropium } 18 \mu \mathrm{g} \text { vs placebo reduced } \\
\text { COPD exacerbations and related } \\
\text { healthcare utilization in patients with } \\
\text { moderate-to-severe COPD }\end{array}$ & Tiotropium vs placebo & 6 months \\
\hline UPLIFT $^{49}$ & $\begin{array}{l}\text { A phase } 3 \text {, randomized, } \\
\text { double-blind, parallel-group, } \\
\text { multicenter, placebo- } \\
\text { controlled trial }(\mathrm{N}=5993)\end{array}$ & $\begin{array}{l}\text { Tiotropium I } 8 \mu \text { improved lung } \\
\text { function, quality of life, and } \\
\text { exacerbations (vs placebo) over } 4 \\
\text { years, but did not significantly reduce } \\
\text { the rate of decline in FEV }\end{array}$ & Tiotropium vs placebo & 4 years \\
\hline TIOSPIR $^{61}$ & $\begin{array}{l}\text { A phase } 3 \text {, double-blind, } \\
\text { parallel-group, multicenter, } \\
\text { randomized controlled trial } \\
(\mathrm{N}=17,135)\end{array}$ & $\begin{array}{l}\text { Tiotropium SMI } 5 \mu \mathrm{g} \text { and } 2.5 \mu \mathrm{g} \text { were } \\
\text { noninferior to tiotropium DPI I } 8 \mu \mathrm{g} \text { for } \\
\text { mortality risk (both } P<0.05 \text { ) and not } \\
\text { superior for exacerbation risk ( } P=0.42 \\
\text { and } P=0.56 \text {, respectively) in this trial of } \\
17, \mid 35 \text { COPD patients }\end{array}$ & $\begin{array}{l}\text { Tiotropium SMI } 5 \mu \mathrm{g} \text { and } 2.5 \mu \mathrm{g} \text { vs } \\
\text { tiotropium DPI } 18 \mu \mathrm{g}\end{array}$ & $\begin{array}{l}2.3 \text { years } \\
\text { mean } \\
\text { follow-up }\end{array}$ \\
\hline \multicolumn{5}{|c|}{ Tiotropium + olodaterol (LAMA + LABA) $)^{88,89}$} \\
\hline WISDOM $^{76,77}$ & $\begin{array}{l}\text { A phase } 4 \text {, double-blind, } \\
\text { parallel-group, multicenter, } \\
\text { randomized controlled trial } \\
(\mathrm{N}=2485)\end{array}$ & $\begin{array}{l}\text { Stepwise ICS withdrawal (fluticasone } \\
\text { propionate) was noninferior to ICS } \\
\text { continuation for risk of moderate or } \\
\text { severe exacerbations in patients with } \\
\text { severe or very severe COPD receiving } \\
\text { tiotropium + salmeterol. ICS } \\
\text { withdrawal resulted in a modest decline } \\
\text { in trough } \mathrm{FEV}_{1} \text {; in patients with high } \\
\text { baseline blood eosinophils, ICS } \\
\text { withdrawal resulted in increased } \\
\text { COPD exacerbations }\end{array}$ & $\begin{array}{l}\text { ICS (fluticasone propionate) } \\
\text { withdrawal vs ICS continuation in } \\
\text { patients on triple therapy (fluticasone } \\
\text { propionate + tiotropium + salmeterol) }\end{array}$ & 52 weeks \\
\hline \multicolumn{5}{|c|}{ Indacaterol + glycopyrronium (LABA + LAMA) ${ }^{99}$} \\
\hline FLAME $^{90}$ & $\begin{array}{l}\text { A phase } 3 \text {, double-blind, } \\
\text { double-dummy, noninferiority, } \\
\text { multicenter, randomized } \\
\text { controlled trial }(\mathrm{N}=3362)\end{array}$ & $\begin{array}{l}\text { Indacaterol + glycopyrronium } \\
\text { significantly lowered the annual rate of } \\
\text { moderate or severe exacerbations and } \\
\text { significantly increased the time to first } \\
\text { moderate or severe exacerbation or } \\
\text { time to first severe exacerbation vs } \\
\text { salmeterol + fluticasone in COPD } \\
\text { patients with a history of at least one } \\
\text { exacerbation in the previous year }\end{array}$ & $\begin{array}{l}\text { Indacaterol + glycopyrronium vs } \\
\text { salmeterol + fluticasone }\end{array}$ & 52 weeks \\
\hline SUNSET ${ }^{72}$ & $\begin{array}{l}\text { A phase } 4 \text {, double-blind, } \\
\text { triple-dummy, parallel-group, } \\
\text { multicenter, randomized } \\
\text { controlled, switch trial } \\
(\mathrm{N}=1053)\end{array}$ & $\begin{array}{l}\text { Direct switch from long-term triple } \\
\text { therapy to indacaterol + } \\
\text { glycopyrronium did not impact COPD } \\
\text { exacerbation risk in low-risk } \\
\text { populations; patients with eosinophil } \\
\text { counts } \geq 300 / \mu \mathrm{L} \text { at both screening and } \\
\text { baseline were more likely to benefit } \\
\text { from continuing triple therapy }\end{array}$ & $\begin{array}{l}\text { Indacaterol + glycopyrronium vs triple } \\
\text { therapy (tiotropium }+ \text { salmeterol }+ \\
\text { fluticasone) }\end{array}$ & 26 weeks \\
\hline
\end{tabular}


Table 2 (Continued).

\begin{tabular}{|c|c|c|c|c|}
\hline $\begin{array}{l}\text { Study } \\
\text { Name }\end{array}$ & Study Type & Study Results & Drug Comparators & Duration \\
\hline \multicolumn{5}{|c|}{ Fluticasone furoate + umeclidinium + vilanterol (ICS + LAMA + LABA) } \\
\hline IMPACT $^{73}$ & $\begin{array}{l}\text { A phase } 3 \text {, double-blind, } \\
\text { parallel-group, multicenter, } \\
\text { randomized controlled trial } \\
(\mathrm{N}=10,355)\end{array}$ & $\begin{array}{l}\text { Fluticasone furoate }+ \text { umeclidinium }+ \\
\text { vilanterol in patients with COPD and } \\
\mathrm{FEV} \text {, predicted }<50 \% \text { normal and } \geq 1 \\
\text { moderate or severe exacerbation } \\
\text { or } \mathrm{FEV} \text {, predicted } 50 \%-80 \% \text { normal and } \\
\geq \text { I severe or } \geq 2 \text { moderate COPD } \\
\text { exacerbations resulted in significantly } \\
\text { lower moderate or severe COPD } \\
\text { exacerbation rates vs fluticasone furoate } \\
+ \text { vilanterol or umeclidinium + vilanterol } \\
\text { in patients with symptomatic COPD }\end{array}$ & $\begin{array}{l}\text { Triple therapy (fluticasone furoate + } \\
\text { umeclidinium + vilanterol) vs } \\
\text { fluticasone furoate + vilanterol or } \\
\text { umeclidinium + vilanterol }\end{array}$ & $\begin{array}{l}\text { 52-week } \\
\text { treatment } \\
\text { period }\end{array}$ \\
\hline \multicolumn{5}{|c|}{ Beclomethasone dipropionate + formoterol fumarate + glycopyrronium bromide (ICS + LABA + LAMA) ${ }^{78,79}$} \\
\hline TRILOGY ${ }^{74}$ & $\begin{array}{l}\text { A phase } 3 \text {, double-blind, } \\
\text { parallel-group, multicenter, } \\
\text { randomized controlled trial } \\
(\mathrm{N}=1368)\end{array}$ & $\begin{array}{l}\text { In symptomatic COPD patients, triple } \\
\text { therapy with beclomethasone } \\
\text { dipropionate }+ \text { formoterol fumarate }+ \\
\text { glycopyrronium bromide significantly } \\
\text { improved predose and 2-hour } \\
\text { postdose FEV, vs beclomethasone } \\
\text { dipropionate }+ \text { formoterol fumarate } \\
\text { dual therapy. Triple therapy also } \\
\text { significantly reduced the adjusted } \\
\text { annual moderate-to-severe } \\
\text { exacerbation frequencies vs dual } \\
\text { bronchodilator therapy }\end{array}$ & $\begin{array}{l}\text { Triple therapy (beclomethasone } \\
\text { dipropionate }+ \text { formoterol fumarate }+ \\
\text { glycopyrronium bromide) vs } \\
\text { beclomethasone dipropionate }+ \\
\text { formoterol fumarate }\end{array}$ & $\begin{array}{l}\text { 52-week } \\
\text { treatment } \\
\text { period }\end{array}$ \\
\hline \multicolumn{5}{|c|}{ Budesonide + glycopyrronium + formoterol fumarate (ICS + LAMA + LABA) } \\
\hline $\mathrm{KRONOS}^{75}$ & $\begin{array}{l}\text { A phase } 3 \text {, double-blind, } \\
\text { parallel-group, multicenter, } \\
\text { randomized controlled trial } \\
(\mathrm{N}=1902)\end{array}$ & $\begin{array}{l}\text { Budesonide }+ \text { glycopyrronium }+ \\
\text { formoterol fumarate MDI triple } \\
\text { therapy was efficacious and well } \\
\text { tolerated and showed improvements, } \\
\text { including reduced COPD exacerbation } \\
\text { rates, vs corresponding dual } \\
\text { bronchodilator therapies in } \\
\text { symptomatic patients with moderate- } \\
\text { to-very severe COPD, irrespective of } \\
\text { exacerbation history }\end{array}$ & $\begin{array}{l}\text { Budesonide + glycopyrronium + } \\
\text { formoterol fumarate via MDI vs } \\
\text { glycopyrrolate }+ \text { formoterol fumarate } \\
\text { or budesonide }+ \text { formoterol fumarate } \\
\text { via MDI, or open-label budesonide + } \\
\text { formoterol fumarate DPI }\end{array}$ & 24 weeks \\
\hline $\mathrm{ETHOS}^{47}$ & $\begin{array}{l}\text { A phase } 3 \text {, double-blind, } \\
\text { parallel-group, multicenter, } \\
\text { randomized controlled trial } \\
(\mathrm{N}=8564 \text { [actual enrollment] })\end{array}$ & $\begin{array}{l}\text { Completed; results awaited. The trial } \\
\text { will assess the efficacy and safety of } \\
\text { triple therapy with budesonide }+ \\
\text { glycopyrronium }+ \text { formoterol fumarate } \\
\text { aerosol provided as MDI vs } \\
\text { corresponding dual bronchodilator and } \\
\text { bronchodilator + ICS therapies for } \\
\text { COPD exacerbations in patients with } \\
\text { moderate-to-very severe COPD }\end{array}$ & $\begin{array}{l}\text { Budesonide }+ \text { glycopyrronium }+ \\
\text { formoterol fumarate }(2 \text { regimens with } \\
\text { different doses) vs budesonide }+ \\
\text { formoterol fumarate or } \\
\text { glycopyrronium }+ \text { formoterol fumarate }\end{array}$ & 52 weeks \\
\hline
\end{tabular}

Abbreviations: COPD, chronic obstructive pulmonary disease; DPI, dry powder inhaler; FEV ${ }_{1}$, forced expiratory volume in I s; ICS, inhaled corticosteroid; LABA, longacting $\beta_{2}$-agonist; LAMA, long-acting muscarinic antagonist; MDI, metered-dose inhaler; SMI, soft mist inhaler. 
Similar to the clinical development of tiotropium, preclinical studies ${ }^{62,63}$ of roflumilast were followed by phase 1 and 2 clinical trials in healthy volunteers and patients with COPD, respectively. ${ }^{64,65}$ In the phase 2 , crossover study, roflumilast significantly reduced the absolute number of neutrophils and eosinophils in the sputum of patients with COPD, and improved postbronchodilator forced expiratory volume in $1 \mathrm{~s}\left(\mathrm{FEV}_{1}\right)$ vs placebo. ${ }^{65}$ Later, results of a large phase $3 \mathrm{RCT}(\mathrm{N}=1411)$ confirmed the efficacy and safety of roflumilast in patients with moderate-to-severe COPD: postbronchodilator $\mathrm{FEV}_{1}$ was improved and exacerbations were reduced ${ }^{66}$ Results of another large RCT ( $\mathrm{N}=1513)$, however, did not demonstrate a reduction in exacerbations despite a significant improvement in lung function. ${ }^{67} \mathrm{~A}$ pooled post hoc analysis of two previous replicate RCTs (including the one reported by Calverley et $\mathrm{al}^{67}$ ) revealed that patients with chronic bronchitis and severe airflow obstruction with or without concurrent ICS use were most likely to benefit from roflumilast. ${ }^{68}$ This understanding subsequently led to two multicenter RCTs in a specific subset of patients with COPD (ie, aged $>40$ years with severe airflow limitation, symptoms of chronic bronchitis, and history of exacerbations). ${ }^{69}$ Indeed, the results demonstrated significant efficacy with roflumilast vs placebo; prebronchodilator $\mathrm{FEV}_{1}$ was significantly improved, and moderate (glucocorticosteroid treated) or severe exacerbations were reduced. In the phase 3/4, postmarketing Roflumilast and Exacerbations in patients receiving Appropriate Combination Therapy (REACT) trial $(\mathrm{N}=1945)$, roflumilast significantly decreased the rate of moderate and severe exacerbations when added to baseline ICS + LABA or triple therapy (LABA + LAMA + ICS) over a period of 1 year in patients with severe COPD, according to prespecified secondary endpoints that considered the use of antibiotics in the definitions. ${ }^{70}$ The primary endpoint (without consideration of antibiotics in moderate-tosevere exacerbations) was not met using Poisson regression (prespecified primary analysis method), although it was met using a negative binomial regression analysis. In the phase 4 Roflumilast Effect on Exacerbations in Patients on Dual (LABA + ICS) Therapy ( $\mathrm{RE}^{2}$ SPOND) trial, roflumilast reduced the rate of moderate and/or severe exacerbations in patients at risk for exacerbations despite treatment with ICS + LABA with or without a LAMA, although the results were not significantly different between the roflumilast and placebo groups. ${ }^{71}$
Large phase 3 RCTs also helped establish robust scientific evidence for efficacy and safety of ICS-containing therapeutic combinations (eg, LABA + ICS in the FLAME trial, LAMA + LABA + ICS in the SUNSET, ${ }^{72}$ IMPACT,${ }^{73}$ TRILOGY, ${ }^{74}$ and $\mathrm{KRONOS}^{75}$ trials) in unique patient populations with COPD.

In addition to evidence generated from clinical trials, practitioners, regulatory authorities, and formulary decisionmakers appreciate RWE generated from observational and pragmatic trials. Examples of real-life COPD administrative database- or claims database-based studies and nonrandomized and randomized COPD PrCTs are summarized in Table 3.

Over the years, findings from observational studies have increased our knowledge and rekindled the evaluation of clinical conundrums by using real-world data to understand the implications of changes in COPD management. For example, the use or withdrawal of ICS and its effects on COPD management have been evaluated in RCTs. ${ }^{72,73,75-79}$ In DACCORD, a real-life, prospective, noninterventional study, patients were treated at the discretion of the physician. ${ }^{80}$ The results were in agreement with similar clinical trials ${ }^{76,99}$ and demonstrated that the risk of exacerbation over 2 years was not increased following ICS withdrawal in patients with low exacerbation risk. However, COPD phenotype groups who do benefit from ICS, including patients with elevated eosinophils and with a history of one or more exacerbations when $\mathrm{FEV}_{1}$ is compromised $\left(<50 \%\right.$ of predicted) ${ }^{77}$ have been identified in large RCTs. ${ }^{73,75,77}$

The findings from large, community-based PrCTs such as the Salford Lung Study in COPD ${ }^{81,82}$ have provided important RWE for COPD pharmacotherapy. The aim of the Salford Lung Study, a 12-month, open-label, randomized (1:1) phase 3 PrCT, was to evaluate the safety and effectiveness of fluticasone furoate + vilanterol (FF + VI; an ICS + LABA combination) vs usual care in patients with COPD and a history of exacerbations $(\mathrm{N}=2799)$ in a real-world setting (75 general practices in Salford and South Manchester, United Kingdom). ${ }^{81,82}$ Use of FF + VI was associated with significantly lower rates of moderate or severe exacerbations without increasing the risk of serious adverse events. ${ }^{82}$ However, the rate of first moderate or severe exacerbation in the time-to-event analysis was not significantly different between groups (hazard ratio for FF + VI vs usual care: 0.93 ; 95\% CI: 0.85-1.02). Limitations of this study included the fact that COPD diagnosis was not confirmed by spirometry, ${ }^{81,83}$ and that the study population for FF + VI did not match the target 
Table 3 Examples of Real-World Studies for COPD Pharmacotherapies

\begin{tabular}{|c|c|c|}
\hline $\begin{array}{l}\text { Study } \\
\text { Name }\end{array}$ & Study Type & Study Aim/Results \\
\hline \multicolumn{3}{|c|}{ Observational studies } \\
\hline DACCORD $^{80}$ & $\begin{array}{l}\text { Real-life, prospective, noninterventional study in which } \\
\text { patients were treated at the physician's discretion }(\mathrm{N}=\mid 258)\end{array}$ & $\begin{array}{l}\text { - No increased exacerbation risk in over } 2 \text { years of follow-up in } \\
\text { patients with ICS withdrawal compared with continuation of } \\
\text { ICS therapies for COPD } \\
\text { - Patient treatment groups may not have been directly compar- } \\
\text { able because of lack of randomization and problems of sever- } \\
\text { ity matching }\end{array}$ \\
\hline OPTIMO9I & $\begin{array}{l}\text { Real-life, prospective study in which patients were treated at } \\
\text { the physician's discretion }(\mathrm{N}=9 / 4)\end{array}$ & $\begin{array}{l}\text { - No increase in exacerbation risk or deterioration in lung function } \\
\text { upon ICS withdrawal from maintenance therapy (ICS + LABA) in } \\
\text { patients with moderate COPD and low exacerbation risk } \\
\text { - Results from prospective randomized controlled trials need } \\
\text { further confirmation because of lack of randomization, vari- } \\
\text { able COPD severity, and cross-over between treatments }\end{array}$ \\
\hline $\begin{array}{l}\text { Samp et al } \\
2017^{92}\end{array}$ & $\begin{array}{l}\text { Retrospective observational study based on an insurance claims } \\
\text { database that included COPD patients in the United States } \\
\text { treated with LAMA + LABA or ICS + LABA }(N=478,772)\end{array}$ & $\begin{array}{l}\text { - LAMA + LABA and LABA + ICS had similar effectiveness as } \\
\text { measured by exacerbation rates in COPD patients }\end{array}$ \\
\hline $\begin{array}{l}\text { Voorham et al } \\
2018^{93}\end{array}$ & $\begin{array}{l}\text { Matched historical cohort study conducted using records from } \\
\text { the OPCRD and CPRD primary care databases }(N=1647)\end{array}$ & $\begin{array}{l}\text { - Significant reduction in exacerbation risk was observed with } \\
\text { triple vs dual bronchodilator therapy, with a larger reduction } \\
\text { in frequent exacerbators }\end{array}$ \\
\hline $\begin{array}{l}\text { Price et al } \\
2018^{94}\end{array}$ & $\begin{array}{l}\text { Matched historical cohort study of real-life management of } \\
\text { COPD patients with or without comorbid asthma } \\
\text { Data from the OPCRD and CPRD primary care databases on } \\
\text { patients prescribed the salbutamol comparator or a reference } \\
\text { product were evaluated }(\mathrm{N}=|19|)\end{array}$ & $\begin{array}{l}\text { - The salbutamol comparator was noninferior to the reference } \\
\text { product for the rate of moderate and severe COPD exacer- } \\
\text { bations after matching for demographic variables, indicators of } \\
\text { disease severity, and baseline maintenance medication }\end{array}$ \\
\hline \multicolumn{3}{|c|}{ Pragmatic nonrandomized controlled trial } \\
\hline $\begin{array}{l}\text { Nyberg et al } \\
2017^{95}\end{array}$ & $\begin{array}{l}\text { Prospective, multicenter, I2-month trial with planned } \\
\text { enrollment of } 96 \text { patients with COPD from six participating } \\
\text { primary care units in Sweden ( } N=96)\end{array}$ & $\begin{array}{l}\text { - Results awaited } \\
\text { procedures that consider the effectiveness of the COPD-web } \\
\text { a novel intervention, which is an internet-based program to } \\
\text { support self-management strategies }\end{array}$ \\
\hline \multicolumn{3}{|c|}{ Pragmatic randomized controlled trial } \\
\hline CRYSTAL $^{96}$ & $\begin{array}{l}\text { Prospective, multicenter, I2-week, open-label, } \mathrm{PrCT} \text { in COPD } \\
\text { patients with moderate airflow limitation }(\mathrm{N}=4389)\end{array}$ & $\begin{array}{l}\text { - Indacaterol + glycopyrronium improved lung function and } \\
\text { dyspnea after direct switch from previous treatments, either } \\
\text { ICS + LABA or LABA or LAMA monotherapy }\end{array}$ \\
\hline $\begin{array}{l}\text { Salford Lung } \\
\text { Study }\end{array}$ & $\begin{array}{l}\text { Prospective, multicenter, I2-month, open-label, phase } 3 \mathrm{PrCT} \\
\text { in COPD patients receiving regular maintenance via inhaler } \\
\text { therapy }(\mathrm{N}=2799)\end{array}$ & $\begin{array}{l}\text { - Fluticasone furoate + vilanterol (ICS + LABA) delivered via a nove } \\
\text { dry powder inhaler lowered the rate of exacerbations vs usual } \\
\text { care without increasing the risk of serious adverse events }\end{array}$ \\
\hline AIRWISE $^{85}$ & $\begin{array}{l}\text { Prospective, multicenter, I2-month, open-label, phase } 4 \text { PrCT } \\
\text { with a planned enrollment of } 3200 \text { patients across community- } \\
\text { based sites ( } N=3200 \text { estimated) }\end{array}$ & $\begin{array}{l}\text { - Results awaited; estimated primary completion date } \\
\text { February 23, 202I } \\
\text { - The aim of the study is to compare the time to first moderate } \\
\text { or severe COPD exacerbation in patients not controlled on } \\
\text { their current therapy, randomized to tiotropium + olodatero } \\
\text { (LAMA + LABA) vs triple therapy (LAMA + LABA + ICS) over } \\
\text { I2 months }\end{array}$ \\
\hline
\end{tabular}

(Continued) 
Table 3 (Continued).

\begin{tabular}{|l|l|l|}
\hline $\begin{array}{l}\text { Study } \\
\text { Name }\end{array}$ & Study Type & Study Aim/Results \\
\hline RELIANCE $^{86}$ & $\begin{array}{l}\text { Multicenter, 36-month, parallel-group, noninferiority, phase } 3 \\
\text { study with a planned enrollment of } 3200 \text { patients }\end{array}$ & $\begin{array}{l}\text { Currently recruiting; estimated primary completion date: } \\
\text { February } 2023\end{array}$ \\
& $\begin{array}{l}\text { The aim of the study is to compare the effectiveness of } \\
\text { roflumilast therapy vs azithromycin to prevent hospitalization } \\
\text { or death in patients at a high risk of COPD exacerbations }\end{array}$ \\
\hline
\end{tabular}

Abbreviations: COPD, chronic obstructive pulmonary disease; CPRD, Clinical Practice Research Datalink; ICS, inhaled corticosteroid; LABA, long-acting $\beta_{2}$-agonist; LAMA, long-acting muscarinic antagonist; OPCRD, Optimum Patient Care Research Database; PrCT, pragmatic clinical trial.

population approved by the regulatory agency. ${ }^{84}$ In addition, $22 \%$ of the subjects receiving FF + VI switched back to their previous regimen. ${ }^{83}$ Although the latter finding is reflective of real-world settings, it complicates the ITT analyses. ${ }^{83}$ Owing to such limitations and the possibility of the Hawthorne effect, ie, altered behavior of patients from awareness of being observed, the classification of the Salford Lung Study as a PrCT and the credibility of its results have been questioned in the literature. ${ }^{84}$ Planned and ongoing PrCTs such as the Assessment In a Real World Setting of the Effect of Inhaled Steroid-based Triple Therapy Versus the Combination of Tiotropium and Olodaterol on Reducing COPD Exacerbations (AIRWISE) ${ }^{85}$ and Roflumilast or Azithromycin to Prevent COPD Exacerbations (RELIANCE) trials ${ }^{86}$ will also add to the accumulating RWE for COPD pharmacological treatments.

Efficacy and safety results of RCTs have been traditionally considered important by clinicians and regulatory authorities alike. However, generalizability of these results is limited because of highly restrictive inclusion and exclusion criteria. On the contrary, effectiveness and long-term safety results provided by real-world studies are accommodative of real-world patient populations and routine clinical practice but have multiple sources of bias for comparisons of multiple treatment arms and questionable internal validity. Considering the strengths and limitations of RCTs and real-world studies, clinicians should make data-driven decisions taking into account results from both types of clinical studies. Moreover, RCT and real-world observational study designs should be complementary in nature, such that, taken together, they provide more robust clinical evidence compared with individual study types. ${ }^{87}$

\section{Conclusion}

In summary, different study designs have their associated advantages and disadvantages. However, when used in concert, findings from various types of studies bring about progress in clinical research. Although RCTs are considered the "gold standard" for evidence on the safety and efficacy of an intervention, observational studies conducted in realworld settings provide evidence on the effectiveness of that intervention in clinical practice. PrCTs help to bridge the gap between classical explanatory RCTs and real-world studies, with a study design that leverages the advantage of randomization in a real-world scenario, thus providing a clearer picture of the safety and effectiveness of a drug.

\section{Acknowledgments}

The authors meet the criteria for authorship as recommended by the International Committee of Medical Journal Editors (ICMJE). The authors received no direct compensation related to the development of the manuscript. Writing, editorial support, and formatting assistance were provided by Vidula Bhole, MD, MHSc, Saurabh Gagangras, PhD, and Maribeth Bogush, MCI, PhD, of Cactus Life Sciences (part of Cactus Communications), which was contracted and compensated by Boehringer Ingelheim Pharmaceuticals, Inc. (BIPI) for these services. BIPI was given the opportunity to review the manuscript for medical and scientific accuracy as well as intellectual property considerations.

\section{Funding}

Financial support for the preparation of this article was provided by Boehringer Ingelheim Pharmaceuticals, Inc. (BIPI). BIPI was given the opportunity to review the manuscript for medical and scientific accuracy as well as intellectual property considerations.

\section{Disclosure}

Dr. Tashkin has participated as an advisory board member and speaker for Boehringer Ingelheim, AstraZeneca, and 
Sunovion. He has also worked as a consultant for Mylan and Innoviva/Theravance. He also reports personal fees from AstraZeneca, outside the submitted work. Dr. Amin has worked as a consultant and/or speaker for Boehringer Ingelheim, Sunovion, BMS, Pfizer, Portola, and AstraZeneca. He also reports personal fees from Boehringer Ingelheim, Sunovion, BMS, Pfizer, Portola, and Astra Zeneca, outside the submitted work. Dr. Kerwin has participated in consulting, advisory boards, and speaker panels for, or has received travel reimbursement from, Amphastar, AstraZeneca, Boehringer Ingelheim, Cipla, GlaxoSmithKline, Mylan, Novartis, Oriel, Pearl, Sunovion, Teva, and Theravance. He has conducted multicenter clinical research trials for approximately 40 pharmaceutical companies. The authors report no other conflicts of interest in this work.

\section{References}

1. Centers for Disease Control and Prevention. Descriptive and analytic studies; 2012. Available from: https://www.cdc.gov/globalhealth/ healthprotection/fetp/training_modules/19/desc-and-analyticstudies_ppt_final_09252013.pdf. Accessed February 26, 2019.

2. Zuidgeest MGP, Goetz I, Groenwold RHH, Irving E, van Thiel GJMW, Grobbee DE. Series: pragmatic trials and real world evidence: paper 1. Introduction. J Clin Epidemiol. 2017;88:7-13. doi:10.1016/j.jclinepi.2016.12.023

3. Clancy MJ. Overview of research designs. Emerg Med J. 2002;19 (6):546-549. doi:10.1136/emj.19.6.546

4. Grimes DA, Schulz KF. An overview of clinical research: the lay of the land. Lancet (London, England). 2002;359(9300):57-61. doi:10. 1016/S0140-6736(02)07283-5

5. U.S._Department_of_Health_and_Human_Services_Centers_for_Dis ease_Control_and_Prevention_CDC. Principles of Epidemiology in Public Health Practice. An Introduction to Applied Epidemiology and Biostatistics. 3 ed. U.S. Department of Health and Human Services_Centers for Disease Control and Prevention (CDC); 2012. Available from: https://www.cdc.gov/ophss/csels/dsepd/ss1978/ SS1978.pdf. Accessed December 12, 2018.

6. Mann CJ. Observational research methods. Research design II: cohort, cross sectional, and case-control studies. Emerg Med J. 2003;20(1):54-60. doi:10.1136/emj.20.1.54

7. Sackett DL. Explanatory and pragmatic clinical trials: a primer and application to a recent asthma trial. Pol Arch Med Wewn. 2011;121 (7-8):259-263.

8. U.S._Department_of_Health_and_Human_Services_Food_and_Drug Administration. The drug development process 2018. Available from: https://www.fda.gov/ForPatients/Approvals/Drugs/default.htm. Accessed May 7, 2020.

9. United States Food and Drug Administration. Inside clinical trials: testing medical products in people; 2014. Available from: https:// www.fda.gov/drugs/drug-information-consumers/inside-clinical-trials -testing-medical-products-people. Accessed March 12, 2020.

10. Hill TP. Conducting phase IV clinical studies: a moral imperative? ecancermedicalscience. 2012;6:276. doi:10.3332/ecancer.2012.276

11. Haque A, Daniel S, Maxwell T, Boerstoel M. Postmarketing surveillance studies-an industry perspective on changing global requirements and implications. Clin Ther. 2017;39(4):675-685. doi:10.10 16/j.clinthera.2017.03.011
12. Suvarna V. Phase IV of drug development. Perspect Clin Res. 2010;1 (2):57-60.

13. Zhang X, Zhang Y, Ye X, Guo X, Zhang T, He J. Overview of phase IV clinical trials for postmarket drug safety surveillance: a status report from the ClinicalTrials.gov registry. BMJ Open. 2016;6(11): e010643. doi:10.1136/bmjopen-2015-010643

14. U.S. Department of Health and Human Services Food and Drug _Administration. Guidance for industry expedited programs for serious conditions - drugs and biologics 2014. Available from: https:// www.fda.gov/downloads/Drugs/GuidanceComplianceRegulatory Information/Guidances/UCM358301.pdf. Accessed May 7, 2020.

15. United States Food and Drug Administration. Non-inferiority clinical trials to establish effectiveness: guidance for industry 2016. Available from: https://www.fda.gov/downloads/Drugs/Guidances/ UCM202140.pdf. Accessed March 14, 2019.

16. Peduzzi P, Henderson W, Hartigan P, Lavori P. Analysis of randomized controlled trials. Epidemiol Rev. 2002;24(1):26-38. doi:10. 1093/epirev/24.1.26

17. Eriksson G, Calverley PM, Jenkins CR, et al. The effect of COPD severity and study duration on exacerbation outcome in randomized controlled trials. Int J Chron Obstruct Pulmon Dis. 2017;12:1457-1468. doi:10.2147/COPD.S130713

18. Sayre JW, Toklu HZ, Ye F, Mazza J, Yale S. Case reports, case series - from clinical practice to evidence-based medicine in graduate medical education. Cureus. 2017;9(8):e1546. doi:10.7759/cureus.1546

19. Garrison LP Jr., Neumann PJ, Erickson P, Marshall D, Mullins CD. Using real-world data for coverage and payment decisions: the ISPOR real-world data task force report. Value Health. 2007;10 (5):326-335. doi:10.1111/j.1524-4733.2007.00186.x

20. Bland JM, Altman DG. Statistics notes: matching. BMJ (Clinical Research Ed). 1994;309(6962):1128. doi:10.1136/bmj.309.6962.1128

21. Tunis SR, Stryer DB, Clancy CM. Practical clinical trials: increasing the value of clinical research for decision making in clinical and health policy. JAMA. 2003;290(12):1624-1632. doi:10.1001/jama.290.12.1624

22. Gamerman V, Cai T, Elsäßer A. Pragmatic randomized clinical trials: best practices and statistical guidance. Health Serv Outcomes Res Methodol. 2018;19:23-25. doi:10.1007/s10742-018-0192-5

23. Woodcock A, Bakerly ND, New JP, et al. The Salford Lung Study protocol: a pragmatic, randomised phase III real-world effectiveness trial in asthma. BMC Pulm Med. 2015;15:160. doi:10.1186/s12890015-0150-8

24. Collins R, Bowman L, Landray M, Peto R. The magic of randomization versus the myth of real-world evidence. N Engl J Med. 2020;382 (7):674-678. doi:10.1056/NEJMsb1901642

25. Anderson ML, Griffin J, Goldkind SF, et al. The Food and Drug Administration and pragmatic clinical trials of marketed medical products. Clin Trials. 2015;12(5):511-519. doi:10.1177/17407745 15597700

26. Loudon K, Treweek S, Sullivan F, Donnan P, Thorpe KE, Zwarenstein M. The PRECIS-2 tool: designing trials that are fit for purpose. BMJ (Clinical Research Ed). 2015;350:h2147. doi:10.1136/ bmj.h2147

27. Goble JA. The potential effect of the 21 st Century Cures Act on drug development. J Manag Care Spec Pharm. 2018;24(7):677-681. doi:10.18553/jmcp.2018.24.7.677

28. Buesching DP, Luce BR, Berger ML. The role of private industry in pragmatic comparative effectiveness trials. J Comp Eff Res. 2012;1 (2):147-156. doi:10.2217/cer.12.9

29. Bogart M, Stanford RH, Laliberte F, Germain G, Wu JW, Duh MS. Medication adherence and persistence in chronic obstructive pulmonary disease patients receiving triple therapy in a USA commercially insured population. Int J Chron Obstruct Pulmon Dis. 2019;14:343-352. doi:10.2147/COPD.S184653

30. Hwang IK, Morikawa T. Design issues in noninferiority/equivalence trials. Drug Inf J. 1999;33(4):1205-1218. doi:10.1177/009286159 903300424 
31. Patsopoulos NA. A pragmatic view on pragmatic trials. Dialogues Clin Neurosci. 2011;13(2):217-224.

32. Moller HJ. Effectiveness studies: advantages and disadvantages. Dialogues Clin Neurosci. 2011;13(2):199-207.

33. Althunian TA, de Boer A, Groenwold RHH, Klungel OH. Defining the noninferiority margin and analysing noninferiority: an overview. Br J Clin Pharmacol. 2017;83(8):1636-1642. doi:10.1111/bcp.13280

34. Schumi J, Wittes JT. Through the looking glass: understanding non-inferiority. Trials. 2011;12:106. doi:10.1186/1745-6215-12-106

35. Jones B, Jarvis P, Lewis JA, Ebbutt AF. Trials to assess equivalence: the importance of rigorous methods. BMJ (Clinical Research Ed). 1996;313(7048):36-39. doi:10.1136/bmj.313.7048.36

36. Patient-Centered Outcomes Research Institute. PCORI dissemination \& implementation framework. Available from: https://www.pcori. org/sites/default/files/PCORI-Dissemination-ImplementationFramework.pdf. Accessed March 9, 2020.

37. National Heart, Lung, and Blood Institute Strategic Visioning. Setting an agenda together for the NHLBI of 2025. Available from: https:// www.ahajournals.org/doi/full/10.1161/CIRCULATIONAHA.115. 015712. Accessed March 9, 2020.

38. Elmes PC, Fletcher CM, Dutton AA. Prophylactic use of oxytetracycline for exacerbations of chronic bronchitis. $\mathrm{Br}$ Med J. 1957;2 (5056):1272-1275. doi:10.1136/bmj.2.5056.1272

39. May JR, Oswald NC. Long-term chemotherapy in chronic bronchitis. Lancet (London, England). 1956;271(6947):814-818. doi:10.1016/ s0140-6736(56)92245-0

40. Vincken W, van Noord JA, Greefhorst AP, et al. Improved health outcomes in patients with COPD during 1 yr's treatment with tiotropium. Eur Respir J. 2002;19(2):209-216. doi:10.1183/090319 36.02.00238702

41. Anthonisen NR, Manfreda J, Warren CP, Hershfield ES, Harding GK, Nelson NA. Antibiotic therapy in exacerbations of chronic obstructive pulmonary disease. Ann Intern Med. 1987;106(2):196-204. doi:10.7326/0003-4819-106-2-196

42. Albert RK, Connett J, Bailey WC, et al. Azithromycin for prevention of exacerbations of COPD. N Engl J Med. 2011;365(8):689-698. doi:10.1056/NEJMoa1104623

43. Nonoyama ML, Brooks D, Guyatt GH, Goldstein RS. Effect of oxygen on health quality of life in patients with chronic obstructive pulmonary disease with transient exertional hypoxemia. Am J Respir Crit Care Med. 2007;176(4):343-349. doi:10.1164/rccm.200702-308OC

44. Nocturnal Oxygen Therapy Trial Group. Continuous or nocturnal oxygen therapy in hypoxemic chronic obstructive lung disease: a clinical trial. Ann Intern Med. 1980;93(3):391-398. doi:10.7326/ 0003-4819-93-3-391

45. Long term domiciliary oxygen therapy in chronic hypoxic cor pulmonale complicating chronic bronchitis and emphysema. Report of the Medical Research Council Working Party. Lancet (London, England). 1981;1(8222):681-686. Available from: https://pubmed. ncbi.nlm.nih.gov/6110912/

46. Albert RK, Au DH, et al.; Long-Term Oxygen Treatment _Trial_Research_Group. A randomized trial of long-term oxygen for COPD with moderate desaturation. N Engl J Med. 2016;375 (17):1617-1627. doi:10.1056/NEJMoa1604344

47. Pearl Therapeutics Inc. Study to assess the efficacy and safety of PT010 relative to PT003 and PT009 in subjects with moderate to very severe COPD (Ethos); 2015. Available from: https://clinical trials.gov/ct2/show/NCT02465567. Accessed December 03, 2018.

48. Niewoehner DE, Rice K, Cote C, et al. Prevention of exacerbations of chronic obstructive pulmonary disease with tiotropium, a once-daily inhaled anticholinergic bronchodilator: a randomized trial. Ann Intern Med. 2005;143(5):317-326. doi:10.7326/00034819-143-5-200509060-00007

49. Tashkin DP, Celli B, Senn S, et al. A 4-year trial of tiotropium in chronic obstructive pulmonary disease. $N$ Engl J Med. 2008;359 (15):1543-1554. doi:10.1056/NEJMoa0805800
50. Gross NJ. Ipratropium bromide. $N$ Engl J Med. 1988;319 (8):486-494. doi:10.1056/NEJM198808253190806

51. Haddad EB, Mak JC, Barnes PJ. Characterization of [3H]Ba 679 BR, a slowly dissociating muscarinic antagonist, in human lung: radioligand binding and autoradiographic mapping. Mol Pharmacol. 1994;45 (5):899-907.

52. Disse B, Reichl R, Speck G, Traunecker W, Ludwig Rominger KL, Hammer R. Ba 679 BR, a novel long-acting anticholinergic bronchodilator. Life Sci. 1993;52(5-6):537-544. doi:10.1016/00243205(93)90312-Q

53. Takahashi T, Belvisi MG, Patel H, et al. Effect of Ba 679 BR, a novel long-acting anticholinergic agent, on cholinergic neurotransmission in guinea pig and human airways. Am J Respir Crit Care Med. 1994;150(6 Pt 1):1640-1645. doi:10.1164/ajrccm.150. 6.7952627

54. Maesen FP, Smeets JJ, Costongs MA, Wald FD, Cornelissen PJ. Ba $679 \mathrm{Br}$, a new long-acting antimuscarinic bronchodilator: a pilot dose-escalation study in COPD. Eur Respir J. 1993;6(7):1031-1036.

55. Littner MR, Ilowite JS, Tashkin DP, et al. Long-acting bronchodilation with once-daily dosing of tiotropium (Spiriva) in stable chronic obstructive pulmonary disease. Am J Respir Crit Care Med. 2000;161 (4 Pt 1):1136-1142. doi:10.1164/ajrccm.161.4.9903044

56. van Noord JA, Bantje TA, Eland ME, Korducki L, Cornelissen PJ. A randomised controlled comparison of tiotropium and ipratropium in the treatment of chronic obstructive pulmonary disease. The Dutch Tiotropium Study Group. Thorax. 2000;55(4):289-294. doi:10.1136/ thorax.55.4.289

57. Caillaud D, Le Merre C, Martinat Y, Aguilaniu B, Pavia D. A dose-ranging study of tiotropium delivered via Respimat Soft Mist Inhaler or Handihaler in COPD patients. Int $J$ Chron Obstruct Pulmon Dis. 2007;2(4):559-565.

58. van Noord JA, Cornelissen PJ, Aumann JL, Platz J, Mueller A, Fogarty C. The efficacy of tiotropium administered via Respimat Soft Mist Inhaler or HandiHaler in COPD patients. Respir Med. 2009;103(1):22-29. doi:10.1016/j.rmed.2008.10.002

59. Bateman E, Singh D, Smith D, et al. Efficacy and safety of tiotropium Respimat SMI in COPD in two 1-year randomized studies. Int J Chron Obstruct Pulmon Dis. 2010;5:197-208.

60. Bateman ED, Tashkin D, Siafakas N, et al. A one-year trial of tiotropium Respimat plus usual therapy in COPD patients. Respir Med. 2010;104(10):1460-1472. doi:10.1016/j.rmed.2010. 06.004

61. Wise RA, Anzueto A, Cotton D, et al. Tiotropium Respimat Inhaler and the risk of death in COPD. $N$ Engl J Med. 2013;369 (16):1491-1501. doi:10.1056/NEJMoa1303342

62. Bundschuh DS, Eltze M, Barsig J, Wollin L, Hatzelmann A, Beume R. In vivo efficacy in airway disease models of roflumilast, a novel orally active PDE4 inhibitor. $J$ Pharmacol Exp Ther. 2001;297(1):280-290.

63. Wollin L, Bundschuh DS, Wohlsen A, Marx D, Beume R. Inhibition of airway hyperresponsiveness and pulmonary inflammation by roflumilast and other PDE4 inhibitors. Pulm Pharmacol Ther. 2006;19 (5):343-352. doi:10.1016/j.pupt.2005.09.002

64. David M, Zech K, Seiberling M, Weimar C, Bethke T. Roflumilast, a novel, oral, selective PDE4 inhibitor, shows high absolute bioavailability. J Allergy Clin Immunol Immunol. 2004;113(2): S220-S221. doi:10.1016/j.jaci.2004.01.246

65. Grootendorst DC, Gauw SA, Verhoosel RM, et al. Reduction in sputum neutrophil and eosinophil numbers by the PDE4 inhibitor roflumilast in patients with COPD. Thorax. 2007;62(12):1081-1087. doi:10.1136/thx.2006.075937

66. Rabe KF, Bateman ED, O'Donnell D, Witte S, Bredenbroker D, Bethke TD. Roflumilast-an oral anti-inflammatory treatment for chronic obstructive pulmonary disease: a randomised controlled trial. Lancet (London, England). 2005;366(9485):563-571. doi:10. 1016/S0140-6736(05)67100-0 
67. Calverley PM, Sanchez-Toril F, McIvor A, Teichmann P, Bredenbroeker D, Fabbri LM. Effect of 1-year treatment with roflumilast in severe chronic obstructive pulmonary disease. Am J Respir Crit Care Med. 2007;176(2):154-161. doi:10.1164/rccm.200610-1563OC

68. Rennard SI, Calverley PM, Goehring UM, Bredenbroker D, Martinez FJ. Reduction of exacerbations by the PDE4 inhibitor roflumilast-the importance of defining different subsets of patients with COPD. Respir Res. 2011;12:18. doi:10.1186/1465-9921-12-18

69. Calverley PM, Rabe KF, Goehring UM, Kristiansen S, Fabbri LM, Martinez FJ. Roflumilast in symptomatic chronic obstructive pulmonary disease: two randomised clinical trials. Lancet (London, England). 2009;374(9691):685-694. doi:10.1016/S0140-6736(09) 61255-1

70. Martinez FJ, Calverley PM, Goehring UM, Brose M, Fabbri LM, Rabe KF. Effect of roflumilast on exacerbations in patients with severe chronic obstructive pulmonary disease uncontrolled by combination therapy (REACT): a multicentre randomised controlled trial. Lancet (London, England). 2015;385(9971):857-866. doi:10.1016/ S0140-6736(14)62410-7

71. Martinez FJ, Rabe KF, Sethi S, et al. Effect of roflumilast and inhaled corticosteroid/long-acting beta2-agonist on chronic obstructive pulmonary disease exacerbations (RE(2)SPOND). A randomized clinical trial. Am J Respir Crit Care Med. 2016;194(5):559-567. doi:10.1164/ rccm.201607-1349OC

72. Chapman KR, Hurst JR, Frent SM, et al. Long-term triple therapy de-escalation to indacaterol/glycopyrronium in patients with chronic obstructive pulmonary disease (SUNSET): a randomized, double-blind, triple-dummy clinical trial. Am J Respir Crit Care Med. 2018;198(3):329-339. doi:10.1164/rccm.201803-0405OC

73. Lipson DA, Barnhart F, Brealey N, et al. Once-daily single-inhaler triple versus dual therapy in patients with COPD. $N$ Engl $J$ Med. 2018;378(18):1671-1680. doi:10.1056/NEJMoa1713901

74. Singh D, Papi A, Corradi M, et al. Single inhaler triple therapy versus inhaled corticosteroid plus long-acting beta2-agonist therapy for chronic obstructive pulmonary disease (TRILOGY): a double-blind, parallel group, randomised controlled trial. Lancet (London, England). 2016;388(10048):963-973. doi:10.1016/S0140-6736(16)31354-X

75. Ferguson GT, Rabe KF, Martinez FJ, et al. Triple therapy with budesonide/glycopyrrolate/formoterol fumarate with co-suspension delivery technology versus dual therapies in chronic obstructive pulmonary disease (KRONOS): a double-blind, parallel-group, multicentre, phase 3 randomised controlled trial. Lancet Respir Med. 2018;6(10):747-758. doi:10.1016/S2213-2600(18)30327-8

76. Magnussen H, Disse B, Rodriguez-Roisin R, et al. Withdrawal of inhaled glucocorticoids and exacerbations of COPD. $N$ Engl J Med. 2014;371(14):1285-1294. doi:10.1056/NEJMoa1407154

77. Watz H, Tetzlaff K, Wouters EF, et al. Blood eosinophil count and exacerbations in severe chronic obstructive pulmonary disease after withdrawal of inhaled corticosteroids: a post-hoc analysis of the WISDOM trial. Lancet Respir Med. 2016;4(5):390-398. doi:10.1016/S2213-2600(16)00100-4

78. Vestbo J, Papi A, Corradi M, et al. Single inhaler extrafine triple therapy versus long-acting muscarinic antagonist therapy for chronic obstructive pulmonary disease (TRINITY): a double-blind, parallel group, randomised controlled trial. Lancet (London, England). 2017;389(10082):1919-1929. doi:10.1016/S0140-6736(17)30188-5

79. Papi A, Vestbo J, Fabbri L, et al. Extrafine inhaled triple therapy versus dual bronchodilator therapy in chronic obstructive pulmonary disease (TRIBUTE): a double-blind, parallel group, randomised controlled trial. Lancet (London, England). 2018;391(10125):1076-1084. doi:10.1016/S0140-6736(18)30206-X

80. Vogelmeier C, Worth H, Buhl R, et al. "Real-life" inhaled corticosteroid withdrawal in COPD: a subgroup analysis of DACCORD. Int J Chron Obstruct Pulmon Dis. 2017;12:487-494. doi:10.2147/ COPD.S125616
81. Bakerly ND, Woodcock A, New JP, et al. The Salford Lung Study protocol: a pragmatic, randomised phase III real-world effectiveness trial in chronic obstructive pulmonary disease. Respir Res. 2015;16:101. doi:10.1186/s12931-015-0267-6

82. Vestbo J, Leather D, Diar Bakerly N, et al. Effectiveness of fluticasone furoate-vilanterol for COPD in clinical practice. $N$ Engl J Med. 2016;375(13):1253-1260. doi:10.1056/NEJMoa1608033

83. Girodet P-O, Raherison C, Molimard M. Effectiveness of fluticasone furoate-vilanterol in COPD. $N$ Engl $J$ Med. 2016;375 (26):2605-2607. doi:10.1056/NEJMc1613713

84. Dal-Re R. Could phase 3 medicine trials be tagged as pragmatic? A case study: the Salford COPD trial. J Eval Clin Pract. 2018;24 (1):258-261. doi:10.1111/jep.12796

85. Boehringer_Ingelheim. The AIRWISE study: assessment in a real world setting of the effect of inhaled steroid-based triple therapy versus the combination of tiotropium and olodaterol on reducing chronic obstructive pulmonary disease (COPD) exacerbations [AIRWISE]; August 2017 [updated December 2017]. Available from: https://clin icaltrials.gov/ct2/show/NCT03265145. Accessed January 2018.

86. National Institutes of Health U.S. National Library of Medicine. Roflumilast or azithromycin to prevent COPD exacerbations (RELIANCE) (RELIANCE; NCT04069312). Available from: https:// clinicaltrials.gov/ct2/show/NCT04069312. Accessed March 9, 2020.

87. Kim HS, Lee S, Kim JH. Real-world evidence versus randomized controlled trial: clinical research based on electronic medical records. J Korean Med Sci. 2018;33(34):e213. doi:10.3346/jkms.2018.33.e213

88. Singh D, Ferguson GT, Bolitschek J, et al. Tiotropium + olodaterol shows clinically meaningful improvements in quality of life. Respir Med. 2015;109(10):1312-1319. doi:10.1016/j.rmed.2015.08.002

89. Calverley PMA, Anzueto AR, Carter K, et al. Tiotropium and olodaterol in the prevention of chronic obstructive pulmonary disease exacerbations (DYNAGITO): a double-blind, randomised, parallel-group, active-controlled trial. Lancet Respir Med. 2018;6 (5):337-344. doi:10.1016/S2213-2600(18)30102-4

90. Wedzicha JA, Zhong N, Ichinose M, et al. Indacaterol/glycopyrronium versus salmeterol/fluticasone in Asian patients with COPD at a high risk of exacerbations: results from the FLAME study. Int J Chron Obstruct Pulmon Dis. 2017;12:339-349. doi:10.2147/ COPD.S125058

91. Rossi A, Guerriero M, Corrado A. Withdrawal of inhaled corticosteroids can be safe in COPD patients at low risk of exacerbation: a real-life study on the appropriateness of treatment in moderate COPD patients (OPTIMO). Respir Res. 2014;15:77. doi:10.1186/1465-992115-77

92. Samp JC, Joo MJ, Schumock GT, Calip GS, Pickard AS, Lee TA. Comparative effectiveness of long-acting beta2 -agonist combined with a long-acting muscarinic antagonist or inhaled corticosteroid in chronic obstructive pulmonary disease. Pharmacotherapy. 2017;37 (4):447-455. doi:10.1002/phar.1913

93. Voorham J, Kerkhof M, Scuri M, et al. Late breaking abstract comparative real world effectiveness of triple therapy versus dual bronchodilation in frequently exacerbating patients with COPD. Eur Respir J. 2018;52(suppl 62). doi:10.1183/13993003.01675-2018

94. Price DB, Gefen E, Gopalan G, et al. Real-life effectiveness and safety of salbutamol Steri-Neb vs. Ventolin Nebules(R) for exacerbations in patients with COPD: historical cohort study. PLoS One. 2018;13(1):e0191404. doi:10.1371/journal.pone.0191404

95. Nyberg A, Wadell K, Lindgren H, Tistad M. Internet-based support for self-management strategies for people with COPD-protocol for a controlled pragmatic pilot trial of effectiveness and a process evaluation in primary healthcare. BMJ Open. 2017;7(7):e016851. doi:10.1136/bmjopen-2017-016851

96. Vogelmeier CF, Gaga M, Aalamian-Mattheis M, et al. Efficacy and safety of direct switch to indacaterol/glycopyrronium in patients with moderate COPD: the CRYSTAL open-label randomised trial. Respir Res. 2017;18(1):140. doi:10.1186/s12931-017-0622-x 
97. Berger ML, Sox H, Willke RJ, et al. Good practices for real-world data studies of treatment and/or comparative effectiveness: recommendations from the joint ISPOR-ISPE special task force on real-world evidence in health care decision making. Value Health. 2017;20(8):1003-1008. doi:10.1016/j.jval.2017.08.3019

98. Singal AG, Higgins PD, Waljee AK. A primer on effectiveness and efficacy trials. Clin Transl Gastroenterol. 2014;5:e45. doi:10.1038/ $\operatorname{ctg} .2013 .13$
99. Rossi A, van der Molen T, Del Olmo R, et al. INSTEAD a randomised switch trial of indacaterol versus salmeterol/fluticasone in moderate COPD. Eur Respir J. 2014;44(6):1548-1556. doi:10.1183/09031936.00126814

\section{Publish your work in this journal}

The International Journal of COPD is an international, peer-reviewed journal of therapeutics and pharmacology focusing on concise rapid reporting of clinical studies and reviews in COPD. Special focus is given to the pathophysiological processes underlying the disease, intervention programs, patient focused education, and self management protocols. This journal is indexed on PubMed Central, MedLine and CAS. The manuscript management system is completely online and includes a very quick and fair peer-review system, which is all easy to use. Visit http://www.dovepress.com/testimonials.php to read real quotes from published authors. 